\title{
The Hands and Feet of the Child: Towards a Philosophy of Habilitation
}

\author{
Eric Anthamatten
}

\section{Abstract}

Much of the history of philosophy has deployed the metaphor of sight over and above language of tactility and feeling. The body, the flesh, the hands and feet are seen as impediments to reason's upward journey towards the pure "light" of truth. But it is precisely these tactile points of contact with the world where knowledge and action begins and ends, and it is the child's curious reaching into and running through the world that must serve as a reminder to the philosopher the origins, termini, and oscillations of the process that is wisdom. Put succinctly, the mind is a hand, and the hand is a mind. Through an exploration of John Dewey's philosophy of habit as articulated in Human Nature and Conduct, this paper emphasizes the need for a philosophy of "habilitation," one that turns to the hands and feet as the major organs of experience, knowledge, self-consciousness, and the ethical encounter with the world and others. When the philosopher amputates the hands and feet from the process of wisdom she severs herself from the very possibility of loving wisdom and eliminates philosophy's potential for analysis, transformation, and action, thus perilously disconnecting philosophy from life itself. 
"The problem with you, Dewey, is that you think philosophy is done with the hands rather than with the eyes."

"Thank you for the compliment."

A child's curious hand: like the budding of a plant seeking nourishment from sun and soil, the hand expresses into the world so that it may give, receive, and reproduce itself: the newborn grasping for mama's breast or papa's nose, instinctually squeezing a finger that may be placed in its palm; the toddler negotiating the traumatic development of its identity by seizing toys and declaring "Mine!"; the painful learning that fire is hot through the necessary experience of placing fingers in flame despite previous verbal warnings; holding hands with grandpa while crossing the road or with other children during a game of ring around the rosy in afternoon play.

It is the child's hands and feet that reciprocally shape mind and world; it is the hands and feet that allow the relationship between mind and world to be possible at all. It is the child in her nonchalant embrace of Being that reminds us-adults, philosophers-that the hands and feet are not peripheral organs that are merely instruments of the will, but rather the very tendrils that make possible will, mind, knowing, and freedom. Though there is a rich tradition in philosophy that emphasizes the hands and feet as organs of knowing, philosophy has been dominated by disembodied notions of reality and thought, paradigms that sever the organism from its world, and metaphors of sight over and above metaphors of tactility and movement. It is no accident that Dewey's persistent critique of these philosophies that divide hand from mind, body from world, knowing from touching often center around issues of education and the child-many of the pseudo-problems fetishized and hyperbolized by philosophy originate precisely in these first moments of education when habits are cultivated that create these amputations and encourage these detrimental divisions. Whole schools of thought emerge and ossify around disembodied notions of being, knowing, and doing, creating paradigms and habitats that in turn reinforce these habits of disconnection and division. A vicious cycle begins, like a crank operated meat grinder that slowly rips the flesh from spirit in the name of freeing spirit from the fetters of flesh. In the end, there certainly is meat without mind. But this is hardly the mind's liberation, for mind without meat, mind without hands and feet, is just as inert, just as lifeless as the flesh from which it was separated.

To be fair, the usual suspects of these divisions and dualisms-Plato, Augustine, Descartes, Kant-may not be so dogmatically dualist as the straw men many critics construct them to be. Careful readings of these thinkers reveal that the issue of the body, the role of the hands and feet in being, knowing, and doing, are more central than a superficial engagement with their philosophies may presume. That and the fact that it is hardly the case that the dualist/disembodied paradigm leads the cart of practice: theory and practice are always dialectically related, both having the ability to reinforce each other, for better or worse, but also having the ability to provide a fulcrum of critique of the status quo. Nonetheless, it has been 
the great error of philosophy, especially the way in has reinforced certain paradigms of education and their concomitant assumptions about the child, to be one of the great cheerleaders of shackling the hands and feet and severing their contact points with the world.

Dewey is a philosopher of the hands and feet, and it is his great task to bring the soul of philosophy out of the ethereal clouds and into the soil that touches soles. It is the child that best epitomizes the fact that the major organs of knowing are the hands and feet, and that the process of learning and experiencing is better understood by the metaphors of touch and movement than by sight and stasis. The mind is a hand, the hand is a mind. The encounter with the world is never passive or unidirectional. "Mind" is no mere container or tabula rasa inside or on which the information of the world is deposited or written. Nor is it an o'erbrimming pot already full of information that only needs a medium through which to "remember" (Plato's anamnesis) or act (Skinner's behavior, the geneticist's DNA). Mind is not a noun, but a verb, a doing, more appropriately conceptualized in statements like "mind your business" or "mommy, Joey's not minding!" We experience, we know, we learn through, to use a Jamesian phrase, a "double-barreled" engagement with the world-we touch and are touched. Mind is prehensile, an embodied activity that reaches into the world and shapes what it knows just as much as it is shaped by what it is knowing. "Knowing" is that constant diaphanous dialogue with the environment, and Being-in-the-world is not a static placement in and on an unmoving Cartesian plane, but instead an osmosis of perceptions, experiences, growths, amputations, blooms, deaths. The mind, especially the mind of a child, is not a camera-it is a catfish, reaching its hundred whiskers into the murky waters of the bayou, literally tasting and smelling everything that it touches, and, in this way, coming to know its world.

Sophia must be allowed to reach and run if she is to be nourished, if she is to grow, if she is to understand the world in which she lives. It is the child that reminds philosophy that it must ultimately return to the hands, feet, and the tactile points of contact with Being. It takes Herculean effort for the child to "learn" these divisions and discontinuities, to stifle the instinct to reach in order to know, to extract itself from the continuous and coordinated flow that is "life." How much of the child's first years involve the commands, "Don't touch!" "Stand still!" "Keep your hands to yourself!" These are not benign rules that are necessary for keeping order and teaching the child to "focus"- they are violent decrees that effectively cut the child from her world, others, and her own development. It is a cruel paradox that the first moments of education are often the moments whereby learning and genuine experience become impossible. Education, the very mechanism whereby we cultivate connections and make possible nutritious experience, becomes the mechanism that makes impossible those enduring connections, cutting and dividing experience and knowledge into tidy discrete cubbyholes, thus placing the child's precious spirit into those cubbyholes alongside their empty shoes and inert crayons. In critiquing 
pedagogy and outlining horizons of educational possibilities, Dewey offers perhaps his most poignant arguments against transcendent metaphysics, dualist epistemologies, and antidemocratic politics. Just as Zarathustra emphasizes that the child is the final and highest metamorphosis of the development of the spirit, so too does Dewey turn to the child as the model for praxis, possibility, and philosophy itself.

\section{The Coordination of Perception}

Dewey emphasizes this relationship between hand and mind, organism and world in his early work "The Reflex Arc Concept in Psychology" (1896). ${ }^{2}$ Here, Dewey critiques the paradigm of the linear-discrete notion of the reflex arc theory of sensation-perception by proposing a circular-continuous model of "co-ordination." It is not to be overlooked that, while a popular example in psychology at the time, an instance involving a child and a hand, namely, a child reaching for the flame of a candle, is at the heart of this essay. Through this example, Dewey tries to show that not only is experience a circuit of activity involving all of the senses, but also that the act of experiencing and learning is caught up in this coordinated circuit, looping back into itself like the thousand threads in a loom as it weaves a tapestry. First, Dewey emphasizes that it is not the sensation that precedes the movement, but rather the movement that precedes the sensation:

Upon analysis, we find that we begin not with a sensory stimulus, but with a sensorimotor co-ordination, the optical-ocular, and that in a certain sense it is the movement which is primary, and the sensation which is secondary, the movement of body, head and eye muscles determining the quality of what is experienced. In other words, the real beginning is with the act of seeing; it is looking, and not a sensation of life. ${ }^{3}$

Dewey, then, implicitly challenges the notion of a rigid separation between the senses, particularly sight and touch, by proposing a seeing-grasping coordination that is inherently part of the child's Being-in-the-world. The child does not see then touch-the child moves, looks (an activity, not passivity), and sees-touches. The act of seeing, for the child, is not yet separated from the act of reaching and touching, or, for that matter, the act of hearing, smelling, and tasting. How many times has a parent had to pull a toy out of a child's mouth? This is not only because they are hungry or teething; it also reveals a deep coordination of the senses, whereby the child comes to investigate and know its world, which is to say, comes to investigate and know itself, through this coordinated, active movement of see-touch-hear-tastesmell. "Now if this act, the seeing, stimulates another act, the reaching, it is because both of these acts fall within a larger co-ordination; because seeing and grasping have been so often bound together to reinforce each other, to help each other out, that each may be considered practically a subordinate member of a bigger co-ordination." The "bigger co-ordination" is not only the senses working in symphonic concert, but the continuous and circular coordination between the child and the 
world. Though we can conceptualize mind and world, psychic and physical, the two "sides" are embedded and enmeshed in this "biggest co-ordination" that we call "life." To extract the organism from this deep connection to its environment-its habitat, its dwelling, its abode-is to risk the organism's death.

Finally, the flame burns the child's hand. This event is not a wholly new one that arises ex nihilo and is rigidly separated from the previous events. Rather, the pain from the flame "is simply the completion, or fulfillment, of the previous eyearm-hand co-ordination." "The injury enters "into the same circuit of experience" of the larger coordinated activity, and only in this way "does the child learn from the experience and get the ability to avoid the experience in the future." "[T]he socalled response is not merely to the stimulus: it is into it."

The circuit does not stop there, for the experience "flame-pain" becomes irrevocably part of the way the child henceforth "sees" candles. That is, the candle no longer is an inert stimulus of light_now, it has an "enlarged and transformed" value. For the moment, flame-light-pain is not experienced as a disconnected series of associations, but an immediately perceived unit. As experiences develop, "flame" comes to have many different values in the flow of consciousness: the blister on the palm; the exhilarating terror when the electricity goes out during the storm; the giddiness of sitting across from a lover during a first dinner together. The quale is never simple, discrete, and linear, but rather always complex, continuous and circular: flame-pain-fear-mystery-joy-love.

The importance of this formative essay for Dewey's later work cannot be overemphasized, not only with regards to his epistemological critiques, but also his critiques of education. ${ }^{7}$ Dewey's vehemence is aimed precisely against pedagogical practices that conceptualize mind and experience as linear-discrete encounters, whereby some bit of information "out there" is stored in some receptor "in here," a model of knowing that creates insurmountable barriers between organism and environment and makes experiencing and learning veritably impossible. Rather, the task of education-the task of philosophy and politics for that matter-is to encourage these connections, to enter into the continuous circuit of experience, to encourage the activity of mind, and to facilitate the process of making connections to one's world, one's culture, one's history, one's experiences. Knowing and learning are always part of this embodied and continuous circuit. If the experience is not sutured into the larger activity, then it lies stillborn, unable to become an object of experience or learning at all. If the conventional reflex arc model is accurate, then children will eternally stick their hands in the flames of candles and be nothing more than dead unlearning stones at the mercy of brute physical forces. So much of what constitutes "teaching and learning" assumes this reflex arc notion of mind. In so doing, this "teaching" makes learning impossible, cutting the organic and continuous flow, literally shortcircuiting experience, electrocuting the organism to its paralysis or death.

"Education" has come to mean the process whereby a child is completely "extracted" from her world, and the school is conceived-theoretically, practically, 
aesthetically_as "apart" from family, community, lived experiences, and history. Windowless classrooms, desks bolted to the floor, locked doors, cameras surveying every corner, metal detectors-Foucault's diagnosis of the deep connections between the school, the prison, the hospital, the asylum, and the military cannot be overstated. The modern classroom has hardly evolved from that of a puritanical country schoolhouse: students are to sit quietly and silently while the teacher writes the lesson on the blackboard, immediately sent to the corner or spanked if they step out of line. Despite the gadgetry of the "smart classroom," there is no real difference other than that the blackboard is now a PowerPoint presentation or a slick YouTube video. And then there are the dangers of disconnection often associated with "distance learning." Being "connected" via technology is only the latest technique of amputation, perhaps more pernicious precisely because it masks itself so seductively and colonizes space and time so incomprehensibly fast.

Consider the image of the student sitting hours in an uncomfortable desk, memorizing multiplication tables or the structure of chemical elements. This is one of the most antihuman and ineffective means of "education," forcing the child to engage with the "information" of the world two-dimensionally, disembodied, disconnected from any value that might have force. Perhaps there is a role for rote memorization in certain circumstances, but it cannot and must not be the point of departure for a serious pedagogy. Ask any Joe in school, "Why are you here?" and the answer will most likely be some variation of "I am here so that I can get $x$. " Education itself is cordoned off from life and is conceived of as a means to some other, remote end. Not just a means, but a painful, boring, all too necessary routine, what Dewey calls the "humdrum," that should be exited as quickly as possible. This is precisely because it is disconnected and experienced only as a discrete "moment along the way" that can be discarded and forgotten when finished. But, just like Dewey's critique of the reflex arc theory of mind, this linear, discrete, "means to an end" approach to education creates no possible learning, experience, connection, or growth. It is no surprise that a "graduate" of this education feels alienated, disconnected, and is perhaps doomed to spend a life sticking his hand in the flame of the candle at age twenty just as he did at age two.

The situation is perhaps more perilous still. If the critique is that education fails to encourage a genuine "hold on" on one's world, oftentimes education not only produces limp and numbed hands-education actively seeks to amputate the hands and feet altogether. The disconnections and disembodiments are not just passive consequences of a certain view of mind and education; rather, this severing from the world is a result of positive techniques encouraged precisely by those educational paradigms. The amputations are many: child from world; child from child; child from adult; child from past; child from present; child from future.

Aristotle writes in De Anima: "the soul is analogous to the hand." If touch is not incorporated into pedagogy, politics, and philosophy, the mind and heart whither without these tactile points of contact-not only the hand reaching to touch 
the world, but also a deep need for this fragile organism to be touched. Touch, in all its modes-loving, violent, indifferent, absent-is not some negligible or secondary aspect of our Being-in-the-world. Touch is nutrition. When we are touched or when we touch, the neurochemistry of joy is released, and a life without touch is just as malnourished as a life without healthy food, exercise, or rest. Indeed, because so close and intimate, touch can become a source of pain and violence, but a life without touch is just as dangerous as a life with only abusive touches.

\section{Habilitation: Habit and Habitat}

Education develops and sustains the life of the mind, and, most importantly, pushes it up and out-like a budding plant, like a child's curious hand and restless feet-up into the sky towards the sun, down into the soil towards the water, and out circumferentially so that it may breathe, photosynthesize, and provide branches for birds and bees. Put differently, education is habilitation, the process of making one "able" to make these connections that facilitate growth, of cultivating ethical "habits," of helping the student to come to have "hold of" her world as well as to recognize the ways in which the world has "a hold" on her, to facilitate the lifelong journey of constructing and maintaining a habitat, a home, a healthy abode.

"Habilitation" comes from the root habere, which means to "have hold of." Habere in turn gives us our word "habit" and "habitat." The relationship of habit to habitat is crucial for Dewey. In Human Nature and Conduct, Dewey emphasizes the dialectal and diaphanous relationship between habit and habitat. ${ }^{9}$ Where Dewey uses the word "environment," I will use the word "habitat" to emphasize the conceptual connection between the organism's habitat and her habits, but also to emphasize the irrevocable tactokinesthetic and embodied nature of this relationship, a relationship that is never at the level of abstractions or ethereal concepts, but always at the concrete points of contact between organism and environment, mind and world, habit and habitat, where hands hold other hands and the "press of the foot to the earth springs forth a hundred affections." 10 Thoughts without feet, after all, stand still and freeze to death in that spot where they stand.

To emphasize the common root habere, to "have hold"-what Dewey calls adaptation or adjustment-points to this deep "hold" that habit and habitat have on each other. First, habitats "have hold of" habits. As individuals and a species, we only adapt insofar as we develop habits that appropriately respond to our habitat. This "natural" habitat is not only the external world into which the organism is thrown - the desert, the jungle, the tundra, the city-but also the more individual "genetic" habitat that both limits and makes possible certain habits that respond to the habitat-physical abilities and abnormalities, tendencies in health, phenotypical structures. Broadly, these can be categorized as habitats of physis. Finally, perhaps most importantly, is the social habitat. This includes the entire range of social habitats that shape our habits: family, friends, community, state. For better or worse, our habits are always shaped by the societies (and their corresponding customs and 
laws) into which we are born, habitats of nomos. Though we may accept, change, or reject those social habitats, we can never shed them completely, nor should we. We are flowers and fruits from the soil and climate in which we grew and inside which we are growing, and like the sunflower or tree, we cannot simply "decide" to uproot and walk to another soil-to do so would be fatal.

But habits are not wholly dependent upon habitat, and the organism is never simply at the mercy of the environment into which it is thrown. Though we are always surrounded by and pressed upon by the objective conditions of habitat, the habit is the organism's active response to free itself from this dependency upon habitat. Habits are never pure and wholly independent acts of will, but are instead "evidence" of the organism's power, freedom, and striving to be more than a dependent and passive object. Habits, then, are that effort to "have a hold of" the habitat. Twigs become nests, trees become huts, the hidden secrets of rocks become jewels or fuel, floods become irrigation, illnesses become motivations to medicine, customs and laws become society, politics, art. The organism is always caught up at the nexus of these vectors of freedom and dependency, passivity and activity, subjectivity and objectivity, the point where habits and habitat touch.

Dewey's theory of habit is a critique of those views of habit and habitat that only acknowledge the primacy of one side of this relationship. One places habitat as the primary determinant of habit, thus making the organism simply a function of physis or nomos. The other imagines that the organism is a will ex nihilo that stands apart and aloof from the world, and that habit is wholly a function of decision and what Dewey calls "metaphysical free will." 11 To have a "bad habit," then, is simply the fault of the individual who does not have the power or perseverance to change that habit. The former disallows any notion of freedom or responsibility; the latter is a fantasy that does not acknowledge the concrete conditions and limitations that make the individual's habits possible in the first place. In practice, it is impossible to separate habit from habitat. It is also fallacious to think of the two in a linear causal relationship. Just as the error of the conventional reflex-arc model is the assumption that perception and the habits that form from those perceptions move in a two-dimensional, unidirectional manner, so too is it erroneous to think that the relationship of habitat-to-habit or habit-to-habitat is overdetermined by one side and only moves in one direction. Habit and habitat operate in a coordination, just like the see-touch-hear-taste-smell coordination of perception and action.

The great misdiagnosis of philosophy has been to break up this coordination, thus severing, at least conceptually, the "hold" that habit and habitat have on each other. The idea that the organism is only habitat, or that there is some completely isolable will that chooses habits ex nihilo, leads to and reinforces practices that create the most egregious and harmful disconnects and alienations of the organism from her self, others, and the world. Perhaps the philosopher must create and maintain a certain theoretical distance from which to diagnose and understand the world. But the philosopher can never "lose hold" of the world, nor let the world lose hold 
of him, jettisoning mind from world, severing hand from habitat, forgetting that all assumptions and habits come from somewhere that is not wholly will or pure reason.

To be "habilitated" is to enter into this dance between habit and habitat in a way that facilitates and nourishes meaningful connections. Habilitation has this treble meaning: to "be able" to develop "habits of character" so that a healthy "habitat" can be constructed. It is this play between habit and habitat, the to-and-fro movement of building Bildung. But the "being able" is something that is primarily made possible by a habitat that allows this ability. As Dewey writes, "To change the working character or will of another we have to alter objective conditions which enter into his habits." ${ }^{2}$ Insofar as the habitat and the habits are detrimental to the organism and the environment, fostering disconnections and divisions, there is nothing more difficult than to extract oneself from this vicious meat grinder of (habit)at. Likewise, a (habit)at that encourages meaningful connections and nourishes the tactile connections of mind and world generate a "virtuous" cycle whereby individual and community, organisms and environment "hold" each other in ways that benefit both elements, an embrace that is exactly what we mean by the concept "love."

Philosophical praxis must encourage this habilitation, and it is only through a genuine pedagogy of the hands and feet that this habilitation is possible: not only the individual's habilitation, but a society's habilitation as well. A community, too, must "be able," must itself develop habits of character and become a living abode where its members feel at home. This is the great task of education, and there is no more potent reminder of this instinct and need for habilitation than the child and her busy hands and restless feet as they so casually create and destroy worlds while at play. Indeed, philosophy and education have a role to play in directing this instinct to habilitation, cultivating it so that connections are deepened and become more meaningful. But philosophy and education must never forget the child, most especially that sacred and precious image of a child's hand. Philosophy must remember that this precious and precarious hold that hand and world have on each other is both the origin and terminus of all endeavors of being, knowing, and doing.

\section{Conclusion}

In closing, it is important to emphasize that Dewey does not advocate a mere "return" to childhood. He is always wary of simply swinging the pendulum to the other side and putting the entire authority with the child. The authority of the teacher and the adult are important for providing direction so that the raw energy and instinct of the child may develop into nutritive experiences. The child is not a nostalgia, but a possibility, a possibility that needs the right amount of direction, order, and discipline that the authority of a teacher can provide. Dewey's critique is against both extremes: too much authority that suffocates and stifles, and none at all, which leads to dispersion and lack of direction. Nonetheless, Dewey does lean towards the child as the source and reminder to teachers, adults, and philosophy itself that the great truth that must be pursued begins and ends with the "live creature," "fully pres- 
ent, all there, in all of its actions. .. . All senses equally on the qui vive." ${ }^{13}$ Again, to refer to Nietzsche's "Three Metamorphoses," the child is a dialectical progression not a reactive regression. There is no "return" to the child, only a development and encouragement of those enthusiasms and vivacities, those sparks of spirit that are symbolized by the child. We can either repress these or develop them into their fullest realization. The child reminds us of that "full presence" whence we began, and demands an education, a politics, and a philosophy that deepens that presence by rooting it to the past so that it may blossom into the future. Thus speaks Zarathustra: "Innocence is the child, and forgetfulness, a new beginning, a game, a self-rolling wheel, a first movement, a Sacred Yes!"14 Let philosophy come play with the child on the beach, discovering new shells and starfish, unworried about how the sand might soil clothes, building castles with the conviction that they will stand forever, but laughing when the surf takes them away. Let philosophy hold hands with the child as they both test their balance against the waves that smash against them. And as they stand or fall, they shout the sacred mantra: "Yes! Life!"

\section{Notes}

1. Quoted in John J. McDermott. The Drama of Possibility (New York: Fordham University Press, 2007), 453.

2. John Dewey, "The Reflex Arc Concept in Psychology," in The Philosophy of John Dewey, edited by John J. McDermott (Chicago: University of Chicago Press, 1981), 137-38.

3. Ibid. 138.

4. Ibid.

5. Ibid.

6. Ibid.

7. "Unless one knows how Dewey diagnoses experience, then his approach to education takes on an obviousness, so castigated by the legions of causal commentators and critics who have never read his work in the round.” John J. McDermott, “The Gamble for Excellence: John Dewey's Pedagogy of Experience," in The Drama of Possibility: Experience as Philosophy of Culture (New York: Fordham University Press, 2007), 414.

8. Aristotle, De Anima, 432a.

9. John Dewey. Human Nature and Conduct (New York: Dover, 2002).

10. Walt Whitman, Leaves of Grass (New York: Penguin, 1959), 36.

11. Dewey, Human Nature and Conduct, 18

12. Ibid., 19.

13. John Dewey, Art as Experience (New York: Perigree Books, 1934), 19.

14. Friedrich Nietzsche, Thus Speaks Zarathustra (New York: Penguin, 1954), 27.

Eric Anthamatten is Teaching Fellow at the New School for Social Research, Trinity College and teaches at Fordham University and John Jay College of Criminal Justice.

E-mail: anthae54@newschool.edu 